\title{
3D Simulation of Vajont Disaster. Part 2: Multi-Failure Scenarios
}

\author{
Alessandro Franci ${ }^{\mathrm{a}}$, Massimiliano Cremonesi ${ }^{\mathrm{b}}$, Umberto Perego $^{\mathrm{b}}$, Eugenio Oñate ${ }^{\mathrm{a}}$, Giovanni Crosta ${ }^{\mathrm{c}}$ \\ ${ }^{a}$ International Center for Numerical Methods in Engineering (CIMNE), Universitat Politècnica de Catalunya (UPC), Carrer Gran Capitán, UPC Campus Nord, \\ Barcelona \\ ${ }^{b}$ Politecnico di Milano, Department of Civil and Environmental Engineering, Piazza Leonardo da Vinci 32, Milan, Italy \\ ${ }^{c}$ Università degli Studi di Milano Bicocca, Department of Earth and Environmental Science, Piazza della Scienza, 4, Milan, Italy
}

\begin{abstract}
Prediction of multi-hazard events requires an informed and judicious choice of the possible scenarios. An incorrect definition of landslide conditions in terms of expected failure volume, material behavior, or boundary conditions can lead to inaccurate predictions and, in turn, to wrong engineering and risk management decisions. Reduced-scale experiments carried out two years before the Vajont disaster were carried out with a material not representative of the actual rockslide behavior and failed in not considering the simultaneous failure of the whole landslide body. Based on these inappropriate assumptions, the physical models led to wrong estimates of the safety operational level for the Vajont reservoir. This work uses the Particle Finite Element Method (PFEM) to analyze the implications of the wrong hypotheses considered in the pre-event experiments, simulating numerically the Vajont disaster for different sliding volumes and material properties. The use of the PFEM for the accurate assessment of the consequences of landslides impinging in water reservoirs has been already validated in a companion paper. In this work, we demonstrate the capabilities of a robust and reliable numerical modeling approach for the simulation of different scenarios assessing what could have been a safe operational reservoir level in the case of a landslide generated impulse wave. The three-dimensional analyses were run with a high mesh resolution and demonstrate the suitability and robustness of the PFEM model for large-scale landslide and multi-hazard events simulation.
\end{abstract}

Keywords:

Rockslides, Rock avalanche, Vajont, PFEM, Impulse Wave, Multi-hazard, Numerical modeling, Collapse scenarios

\section{Introduction}

The slopes along the shoreline of large water bodies represent an important risk factor at many sites worldwide. Water impounding and rapid drawdown of the water reservoir cause a decrease in the safety factor of the slopes and the triggered instability could be at the origin of multi hazards which can have extreme consequences on the environment. These events can strongly affect the population, structures and infrastructures located in the immediate proximity or at a large distance from the slopes. About 57,000 large dams exist worldwide (ICOLD) and this suggests the size of this potential problem. Furthermore, we must consider that the same type of hazard and risk level (or even larger) can be found in fjordland areas where steep slopes stand directly over large water bodies. These data motivate the need to study carefully the slope stability and the possible consequences associated with a potential failure that could impact the water reservoirs. The construction of a sound conceptual model of the expected slope failure and the building of a set of reasonable and possible scenarios, including the multi-hazard one, are then mandatory. At the same time, the development of experimental and numerical tools for the analysis of these scenarios and the prediction of their consequences is fundamental to support the designers, as well as all the involved stakeholders. Following a companion paper (Franci et al., 2020), the Vajont catastrophic event is here reexamined to suggest what went wrong in the experimental predictions on the possible Vajont rockslide and to show how a reliable numerical model could have supported the building of a more complete view of the possible consequences and, in turn, the stakeholders' decisions.

The Vajont disaster occurred in the north-east of Italy on the night of the $9^{\text {th }}$ of October 1963. A massive rockslide of about 275 million cubic meters detached from the Mount Toc and impinged into the underlying water reservoir of the Vajont dam, generating huge waves in the hydroelectric basin. A large part of the impounded water volume (about $25 \cdot 10^{6} \mathrm{~m}^{3}$ according to Selli and Trevisan (1964) and Viparelli and Merla (1968)) overtopped the dam crest (altitude $725 \mathrm{~m}$ ) causing extensive damages to the villages placed downstream the dam. In the disaster, about 2000 people lost their life.

The rockslide occurred during the third filling-drawdown cycle of the hydroelectric reservoir. After reaching the maximum altitude of $710 \mathrm{~m}$ on the $26^{\text {th }}$ September 1963 (Paronuzzi et al., 2013), the water level was decreased quickly after noticing that the rates of movement of the active landslide were critically increasing. Unfortunately, this could not avoid the disaster that occurred thirteen days later when the water was at about $700 \mathrm{~m}$ above the sea level (a.s.l.).

The instability of the northern side of Mount Toc was recognized years before the disaster. In March 1960, less than one year after the completion of the dam (September 1959) and more than three years before the disaster, a first landslide oc- 
curred on the left slope during the first filling of the reservoir. At the end of the same year, a huge continuous crack opened on the northern slope of the Mount Toc. This impressive M-shaped $1 \mathrm{~m}$ wide and $2.5 \mathrm{~km}$ long fracture (known as the Muller's $M$ ) marked the contour of a huge sliding mass composed of two distinguishable bodies (the eastern and western lobes) separated each other by the Massalezza creek.

These hazardous phenomena induced the S.A.D.E.-Adriatic Energy Corporation, owner of the Vajont hydroelectric plant, to take into serious consideration the possibility of a landslide impacting the hydroelectric reservoir. For this reason, S.A.D.E. commissioned Prof. Ghetti (Institute of Hydraulics, University of Padua) to study hypothetical scenarios of landslide impulse waves in the Vajont basin in order to establish the safe water level of the hydroelectric reservoir.

Between 1961 and 1962, Ghetti realized a series of tests on a 1:200 scaled physical model of the reservoir considering different types of sliding surfaces, initial impounded water levels, and landslides volumes. Nevertheless, all the experimental tests considered the collapse of either the eastern or the western sectors of the landslide separately and never the simultaneous and sudden failure of the whole rockslide body (Ghetti, 1962). Furthermore, only the use of gravels for the sliding material was investigated. Under these conditions, in the most critical case, the maximum wave runup was about $30 \mathrm{~m}$ and it was localized in the area directly facing the rockslide, whereas, in the rest of the reservoir, the maximum runup was around $10 \mathrm{~m}$. This physical modeling campaign concluded that the reservoir altitude of $700 \mathrm{~m}$ could be considered as a level of "absolute safety" versus for the scenario of a landslide impacting directly the water reservoir (Ghetti, 1962). Tragically, the rockslide occurred when the water in the reservoir was at about that level but produced a runup much higher than the predicted one: more than $200 \mathrm{~m}$ in front of the landslide and not less than $40 \mathrm{~m}$ in the rest of the lake shoreline (Viparelli and Merla, 1968).

Many reasons may explain the large discrepancy between the pre-event experimental predictions and post-event observations. Nevertheless, probably the major limitations of these tests consisted of considering the separate collapse of the landslide lobes (each one about one half of the entire rockslide) and the used of rounded gravel to simulate the real rockslide mass.

Nevertheless, it should be remarked that even some postfailure experimental works were characterized by strong limitations in the model geometry and adopted materials (see the summary presented in Crosta et al. (2016)).

Numerical modeling allows to circumvent many of the problems associated with physical models offering much more flexibility in terms of problem scale, material characteristics, geometry, and boundary conditions (Pudasaini and Mergili, 2019). This work aims to study the implications of the assumptions made at the time of the event through an efficient numerical model. Furthermore, in order to assess what could have been an operational safe water level of the Vajont reservoir versus a landslide impulse-wave scenario, simulations with different initial reservoir water levels were performed.

These analyses were carried out with the Particle Finite Element Method (PFEM (Idelsohn et al., 2004; Oñate et al.,
2004)). The PFEM is a numerical approach designed to solve large deformation problems in continuum mechanics. The method combines efficiently a fully Lagrangian Finite Element Method (FEM) solver with a fast remeshing algorithm. The well-suited combination of these two features makes the PFEM an ideal tool for the simulation of landslide impulse wave events, as shown in several previous publications (Salazar et al., 2016; Cremonesi et al., 2011, 2017; Zhang et al., 2019; Mulligan et al., 2020). Indeed, on the one hand, the Lagrangian description of the motion allows for a faithful tracking of the deforming shapes of both the landslide and the water bodies and their mutual interfaces, and, on the other hand, the use of a FEM-based solver enables the accurate solution of the complex constitutive behavior used for the landslide material. This represents an important advantage against both conventional Eulerian FEM methods, which require specific techniques for tracking the material interfaces (such as the Level Set method Osher and Fedkiw (2006)), and to other Lagrangian particle-based methods, such as the Smoothed Particle Hydrodynamics (SPH) Gingold and Monaghan (1977), that smooths the material properties with specific kernel functions, resulting inevitably in a less accurate solution than a FEM strategy.

In a companion paper (Franci et al., 2020), a PFEM model based on the implicit formulation developed by the authors (Oñate et al., 2014; Franci and Zhang, 2018; Franci and Cremonesi, 2019), was validated for three-dimensional (3D) landslide impulse wave events and applied to the numerical simulation of the Vajont disaster with a full 3D model. We note that, despite the large number of numerical models applied to the Vajont disaster (e.g. Ward and Day (2008), Ward and Day (2011), Manenti et al. (2016), Manenti et al. (2018), Bosa and Petti (2011), Bosa and Petti (2013), or Pinyol et al. (2017)), at the best of the authors' knowledge, only two other 3D simulations of the Vajont disaster are reported in the literature, i.e. Vacondio et al. (2013) and Crosta et al. (2016). Nevertheless, in Vacondio et al. (2013) only the water motion was modeled whereas the landslide was simulated as a rigid body with a prescribed motion, while in Crosta et al. (2016) both the landslide and water were modeled with an Arbitrary Lagrangian Eulerian FEM but with a mesh of lower resolution than the one used in this work.

Based on an adequately refined three-dimensional mesh and on the PFEM modeling of the landslide and the water, Franci et al. (2020) reproduced with a certain accuracy the phenomena occurred during the Vajont disaster: the detachment, runout, and stoppage of the rockslide, the $200 \mathrm{~m}$ water runup on the northern flank of the valley, the upstream propagation of the tsunami wave along the residual Vajont lake, and the water volume overtopping the dam. The PFEM results were in good agreement with the post-event measurements and observations. These results justify the use of this 3D PFEM model as reference for the alternative scenarios of the Vajont disaster here considered, i.e. the separated collapse of the eastern and western lobes of the Vajont rockslide, and the study of the dynamics for different initial water levels of the reservoir. We further check the effects of the adoption of a gravel material (i.e. Ghetti's experimental setting) versus the case of the rockslide 
(a) Initial mesh

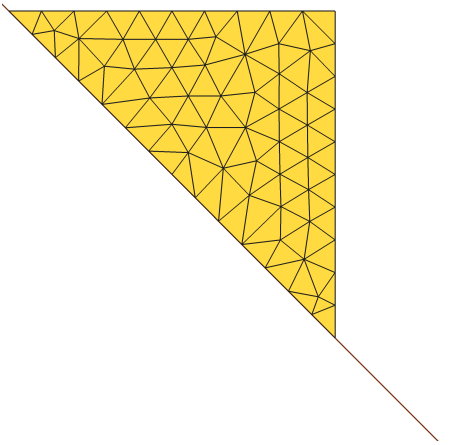

(b) Mesh after the computation

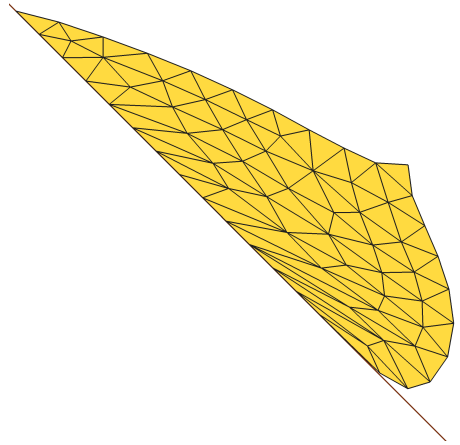

(c) Mesh after remeshing

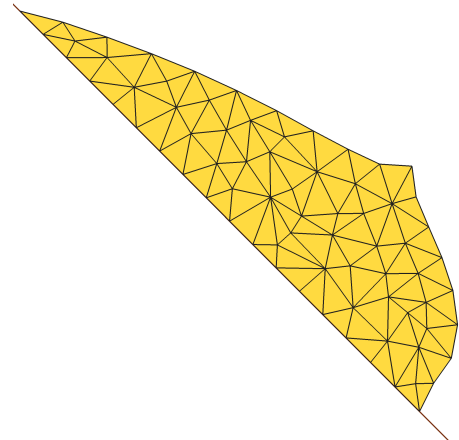

Figure 1: PFEM solution scheme. (a) Initial mesh used for computation. $(b)$ Mesh after the time step computation and the Lagrangian motion of the nodes. $(c)$ Mesh at the beginning of the next time step after applying PFEM remeshing.

simulated with the set of material parameters used in Franci et al. (2020).

The paper is structured as follows. In Section 2, a concise description of the PFEM is given. Section 3 describes the Vajont rockslide event with special attention on the geological setting (Section 3.1), the overall disaster dynamics and post-event observations (Section 3.2), and the pre-event experiments done with a scaled physical model (Section 3.3). Section 4 is devoted to the numerical simulations. In Section 4.1, the separated collapse of east and west lobes is analyzed: first, in Section 4.1.1, considering realistic material parameters for the rockslide, then, in Section 4.1.1, using gravel as the sliding material like in the pre-event experiments. Finally, Section 4.2 analyzes the hypothetical scenario of three different initial water levels in the reservoir. The conclusions of the work are given in Section 5.

\section{Solution scheme with the PFEM}

In this work, landslide and water are both modeled with the Particle Finite Element Method (PFEM) (Idelsohn et al., 2004; Oñate et al., 2004). Details of the PFEM are provided in the companion paper (Franci et al., 2020) and in previous publications where the method was applied to free-surface fluid dynamics problems for Newtonian (Oñate et al., 2014) and nonNewtonian (Franci and Zhang, 2018) flows, fluid-structure interaction applications (Franci et al., 2016), and to dense granular material simulation (Franci and Cremonesi, 2019). In this work, we will only recall the main characteristics of the PFEM. Interested readers are referred to the mentioned publications for more information.

The PFEM is a purely Lagrangian FEM-based method suitable for large deformation analysis in solid and fluid mechanics. The mesh distortion issues arisen from the Lagrangian description of the deforming body, are solved by a special remeshing strategy (Cremonesi et al., 2020). This procedure combines the Delaunay Triangulation algorithm (Edelsbrunner and Tan, 1993) with the Alpha Shape method (Edelsbrunner and Mucke, 1999), a technique employed for the identification of the boundaries of the computational domain. This peculiar remeshing method allows for the automatic detection of evolving fluid surfaces and fluid-solid interfaces. In the context of this work, this is an extremely useful technique to track accurately both the landslide shape during the runout and the water free surface.

In Fig. 1, a qualitative graphical representation of the PFEM solution algorithm is provided. The mesh shown in Fig. 1a is used as the support for the time step computation with the FEM. In the PFEM, the mesh nodes are treated as material particles and they move in a Lagrangian way according to the equations of motion. Fig. $1 \mathrm{~b}$ shows the mesh configuration at the end of the time step computation. The excessive distortion of the FEM discretization makes it necessary to rebuild the mesh. Note that the remeshing procedure is invoked only when the mesh distortion overcomes a pre-fixed threshold. Fig. 1c shows the discretization after remeshing. The nodes of the previous mesh are kept fixed but the connectivity has changed improving the quality of the elements. Note that during this step also the new solid interfaces are detected.

The landslide mechanics and its interaction with the reservoir water are modeled using a fluid dynamics approach. The problem is governed by the linear momentum balance and mass conservation equations. For the FEM solution, linear shape functions are used for the nodal unknowns of the problem, i.e. the velocities and the pressure. To overcome the numerical instabilities arisen by the unfulfillment of the inf-sup condition in incompressible fluids (Brezzi and Fortin, 1991), the numerical solution is stabilized with the Finite Increment Calculus (FIC) method (Oñate et al., 2014). Each time increment is solved iteratively with an implicit two-step algorithm.

Concerning the constitutive models, a standard Newtonian law is used for the water, while a regularized frictional viscoplastic model is employed for the landslide material. In both cases, the Cauchy stress tensor is computed as the sum of its deviatoric and volumetric parts as

$$
\sigma_{i j}=\tau_{i j}-p \delta_{i j}
$$

where $p$ is the pressure, $\delta_{i j}$ is the Kronecker delta, and $\tau_{i j}$ is the deviatoric stress tensor that is computed for both water and 
landslide as

$$
\tau_{i j}=\bar{\mu} \dot{\gamma}_{i j}
$$

where $\bar{\mu}$ is the apparent viscosity and $\dot{\gamma}_{i j}$ is the deviatoric strain rate, which, considering as negligible the volumetric deformation, is obtained from the velocities as

$$
\dot{\gamma}_{i j}=\frac{\partial v_{i}}{\partial x_{j}}+\frac{\partial v_{j}}{\partial x_{i}}
$$

For water, the apparent viscosity $\bar{\mu}$ (Eq.(2)) coincides with the fluid dynamic viscosity $\mu$. Hence:

$$
\bar{\mu}_{w}=\mu
$$

Instead, for landslide material the apparent viscosity is computed using the following frictional viscoplastic model (Franci et al., 2020)

$$
\bar{\mu}_{l a n}=\frac{c+p \tan (\phi)}{|\dot{\gamma}|}\left(1-e^{-m|\dot{\gamma}|}\right)
$$

where $c$ is the cohesion, $\phi$ is the friction angle, $m$ is a regularization parameter (set as equal to 1000s in all the analyses), and $|\dot{\gamma}|=\sqrt{\frac{1}{2} \dot{\gamma}_{i j} \dot{\gamma}_{i j}}$ is the equivalent strain rate.

\section{Vajont rockslide}

\subsection{Geological setting}

The Vajont rockslide affected the northern slope of Monte Toc (Venetian southern Alps) along the left-hand side (i.e. southern flank) of the Vajont valley (Fig. 2a) where the JurassicCretaceous carbonate sequences outcrop (Semenza, 1965). The rockslide is limited at its bottom by the Vajont oolitic limestone which is not directly affected by the rockslide. The rockslide mass is formed by the cherty limestone of the Fonzaso Formation (Oxfordian-Callovian, 10-40m) which includes some thin interlayers of yellowish to greenish high plasticity montmorillonitic clays, the fossiliferous nodular Rosso Ammonitico limestone (Titonian-Kimmeridgian, 0-15m), the massive Soccher limestone to marly and cherty limestone (Cretaceous, 150$250 \mathrm{~m}$ ) which forms the largest part of the rockslide mass, and finally the Scaglia Rossa marly limestones (Upper CretaceousEocene, about 300m).

Semenza (1965) and Rossi and Semenza (1965) mapped the geology on both valley flanks, both before and after the 1963 collapse, recognizing the presence of the same sequence at the valley bottom and the buried (i.e. epigenetic) valley infilled by a paleolandslide deposit (see cross-section in Fig. 2 b corresponding to Section 2 by Rossi and Semenza (1965)). Massironi et al. (2013) described the sliding surface as generated by the interference of the East-West $(E-W)$ trending Erto Syncline and the North-South $(N-S)$ trending Massalezza Syncline. An interesting observation by Massironi et al. (2013) concerns the continuity of these twofold systems both within and outside the rockslide mass, demonstrating how these predate the rockslide. This suggests that a relatively limited deformation occurred within the rockslide mass during both the prehistoric (a) Plan view

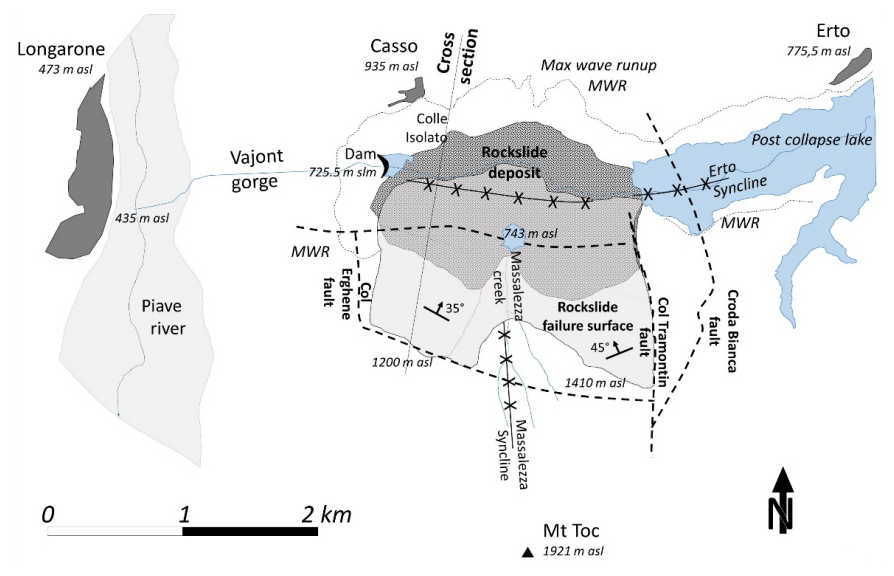

(b) Cross section

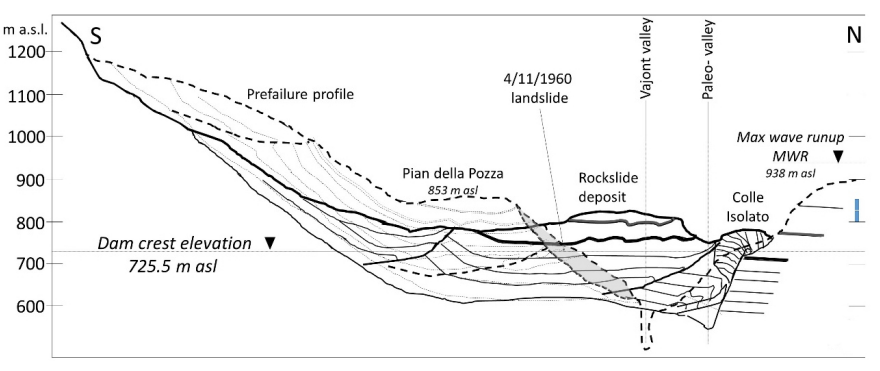

Figure 2: Pre- and post-failure view of the Vajont landslide area. (a) Plan view. (b) Representative cross section.

and the recent Vajont rockslides. So a relatively localized shear zone or damage zone developed probably during the prehistoric rockslide and has been partially or totally reactivated by the modern 1963 Vajont rockslide. The twofold systems controlled the rockslide failure surface geometry (Fig. 2b). The Erto syncline generates the famous chair like geometry which characterizes the geologic cross-sections of the landslide. The Massalezza syncline is probably at the origin of the Muller Mshaped scarp and it could have partially controlled the failure mode and sequence by providing a slight convergent component to the motion of the two masses located at East and West of the Massalezza creek. Two subvertical faults were mapped in the area: the $E-W$ trending Col delle Erghene Fault and the $N-S$ trending Col Tramontin Fault which form the southwestern and the eastern limits of the prehistoric rockslide, respectively.

\subsection{Disaster dynamics and post-event observations}

The Vajont rockslide spread northward and displaced the water filling the underlying hydroelectric reservoir, whose level whose at about $700 m$ a.s.l. at the time of the event (Semenza, 1965). In Fig. 3, a recent photo of the Vajont valley is provided. The picture taken from the northern flank of the valley shows the huge amount of mobilized material that has filled the hydroelectric reservoir, the slip surface without vegetation on the northern flank of the M. Toc, and, in the right-hand side, the crest of theVajont dam, which was only partially damaged 
during the accident. About 170 million cubic meters of water

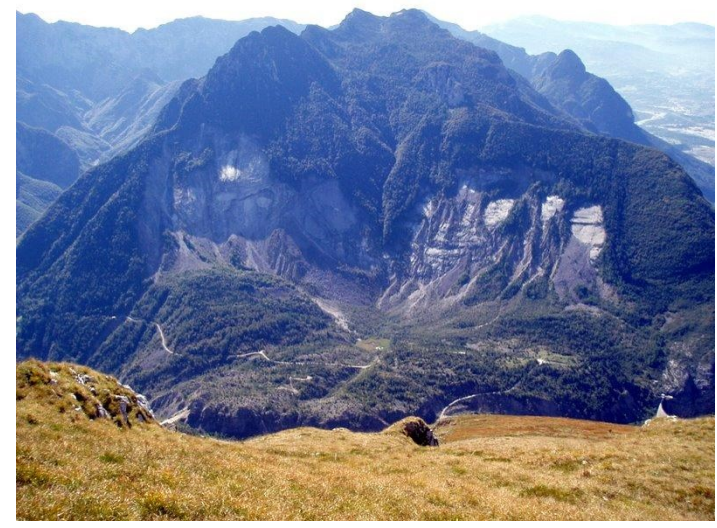

Figure 3: Recent photo of the Vajont valley taken from the northern flank.

were pushed upwards on the opposite side of the Vajont valley, reaching a remarkable runup of more than $200 \mathrm{~m}$ (Viparelli and Merla, 1968). The village of Casso placed at an elevation of about $950 m$ a.s.l. was brushed by this first huge wave. A part of the enormous quantity of impounded water volume overflew the dam crest ( $725 m$ a.s.l.) with an estimated flow rate of about $10^{5} \mathrm{~m}^{3} / \mathrm{s}$ (Viparelli and Merla, 1968). This large amount of water, after flowing through a narrow and steep gorge of about $1.5 \mathrm{~km}$ long, reached the Piave valley, bringing solid debris of different size, and destroyed almost entirely the village of Longarone (473m a.s.l.). Another significant part of the water volume generated a large impulse wave in the Vajont reservoir that propagated eastward causing a water runup not lower than $40 \mathrm{~m}$ on all the shores of the lake (Viparelli and Merla, 1968). The village of Erto, located to the north-eastern limit of the lake (see Fig. 2a), was the most affected by this tsunami-type wave.

Concerning the rockslide dynamics, it has been estimated that the landslide moved about $360-450 \mathrm{~m}$ to the north and about $140 \mathrm{~m}$ uphill on the opposite valley flank with a velocity of 1530m/s (Muller, 1964; Selli and Trevisan, 1964; Ciabatti, 1964; Voight and Faust, 1982; Hendron and Patton, 1985; Nonveiller, 1987). The triggered mass was the entire volume enclosed by the M-shaped crack (Muller's M) that was formed at the end of 1960. According to different authors (Selli and Trevisan, 1964; Ciabatti, 1964; Datei, 1969; Viparelli and Merla, 1968), the overall volume of the mobilized material was about 275 million cubic meters.

\subsection{Pre-event predictions through a scaled physical model}

Two years before the disaster, after the first signs of instability of the northern side of the Mount Toc, the S.A.D.E. Corporation, owner of the Vajont hydroelectric plant, commissioned Ghetti to examine the hydraulic effects of an eventual landslide impacting the Vajont reservoir by a physical model. The 1:200 scaled physical model was completed at the end of the summer of 1961 and during the following year was used to analyze plausible scenarios of landslide spreading on the water reservoir. Several different configurations were considered in these tests.
In particular, three water levels $(722.5 \mathrm{~m}, 700 \mathrm{~m}$, and $670 \mathrm{~m}$ a.s.l.) and different types of failure surfaces were considered, from a planar slope with a variable inclination of $30^{\circ}-42^{\circ}$ to a more complicated chair-like surface. Due to the technical difficulties of realizing the experimental tests with a visco-plastic material (Ghetti, 1962), rounded gravel 8-10mm in diameter was always used for the sliding mass. The landslide material was initially contained through a metallic net and successively released under the only effect of gravity whereas, in some cases, a specific pulling system designed to control landslide velocity and duration was used. In all cases, the total time was never less than $61 s$ (Ghetti, 1962), i.e. much higher than the estimated duration of the real event. A literature summary of the estimated duration of the Vajont rockslide is reported in Dykes and Bromhead (2018).

Taking into account the different geological conditions of the slop masses placed to the east and west of the Massalezza creek (see Fig. 2), the experiments always considered the separated failure of eastern and western lobes of the landslide and never their simultaneous collapse, as later observed in the real event. The sequential failure of the two lobes was only simulated to consider the possible constructive interference of the generated waves. Table 1 collects the results of Ghetti's experiments for a water level of $700 m$ a.s.l.. The table reports the triggered part of the landslide (i.e. the lobe), the duration of the sliding motion, and the maximum wave amplitude measured at the dam position and in the rest of the reservoir.

The results show that the most critical situation for an initial reservoir level of $700 \mathrm{~m}$ was reached in the last test of the series (the $19^{\text {th }}$ test according to the numbering of Ghetti (1962)). At the beginning of this experiment, the eastern lobe was released for a total duration of 3 minutes. Then, after a pause of 9 minutes, also the western lobe was released for an overall sliding duration of 1 minute. Under these conditions, the maximum water runup along the lake shoreline was of only $31.4 \mathrm{~m}$. At the dam position, the wave amplitude was $27 \mathrm{~m}$, giving an overtopping wave height of just $2 \mathrm{~m}$. Unfortunately, these results lead to the wrong conclusion of considering the water level of $700 \mathrm{~m}$ as a safe operational condition for the Vajont reservoir.

\section{Numerical simulations}

Fig. 4 shows a top view of the Vajont computational domain considered in this work. The dimensions of the analyzed geometry are $3 \mathrm{~km}$ and $4 \mathrm{~km}$ in north-south and west-east directions, respectively (coincident with the directions of the $x, y$ axes, whose origin is placed at the easternmost point of the dam crest). Water fills the reservoir up to a height of $700 \mathrm{~m}$ a.s.l. (as it was at the moment of the real rockslide). In the figure, the western and the eastern lobes of the landslide have been highlighted with different colors and the position of sections $A, B$, $C$, and $D$ is also shown. Section A is placed at $y=500 m$ and it is used to analyze the dynamics of the western part of the landslide, while sections $B, C$ and $D$ are used to monitor the upstream wave propagation and they are placed at $y=2240 \mathrm{~m}$, 2450 , and $2840 m$, respectively. 


\begin{tabular}{cccccc} 
Triggered Portions & Dam overtopping & \multicolumn{2}{c}{ Sliding duration [s] } & \multicolumn{2}{c}{ Maximum wave amplitude [m] } \\
\hline West lobe & & $\mathbf{1}^{\text {st }}$ & $\mathbf{2}^{\text {nd }}$ & At the dam & Rest of the reservoir \\
\hline East lobe - Stop - West lobe & No & 225 & - & 10.4 & 8.8 \\
West lobe & No & 110 & 130 & 14.2 & 13 \\
West lobe & No & 120 & - & 13.2 & 10 \\
West lobe & No & 63 & - & 17 & 13.4 \\
East lobe - Stop - West lobe & Yes $\left(21 \cdot 10^{3} \mathrm{~m}^{3}\right)$ & 180 & 60 & 20.6 & 20.7 \\
\end{tabular}

Table 1: Results and landslides features of pre-event experiment for reservoir level of 700m a.s.l.. Numerical values are taken from Ghetti (1962).

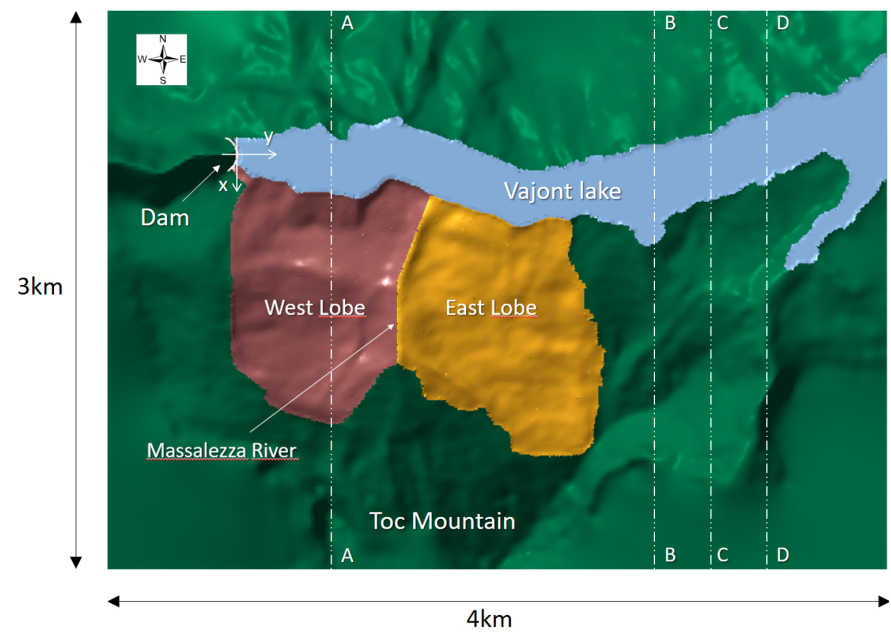

Figure 4: Computational domain and location of the cross sections used for the analysis of the results.

In this work, we first focus on the separate collapse of the eastern and western lobes of the rockslide with the water level at $700 m$ a.s.l. (Section 4.1), and then on the simultaneous collapse of both lobes for three different initial water levels in the reservoir (Section 4.2). For all cases, the results presented in Franci et al. (2020) and obtained considering the whole landslide body and an initial water reservoir level of $700 \mathrm{~m}$ will be used as reference for comparisons. The analyses were run for a total time duration of $100 \mathrm{~s}$ and using a mean element size of $10 \mathrm{~m}$ for the first discretization of the computational domain (as in Franci et al. (2020)). We remark that so far, this represents the finest mesh used for a fully-resolved 3D analysis of the Vajont disaster.

To better appreciate the slip surface considered in this work, a planar view of the computational domain without the landslide and water body is provided in Fig. 5 together with the information about the level curves. The sliding volume and slip surface are the same as the ones used in Crosta et al. (2016) and were defined by combining the pre-failure and post-failure data of available geological cross-sections (Rossi and Semenza, 1965), topographic maps (Rossi and Semenza, 1986), Lidar surveys (provided by the Regione Friuli Venezia Giulia), and borehole data (Broili, 1967).

The rockslide was modeled with the frictional visco-plastic law given in Eq. 5 and using two different sets of parameters

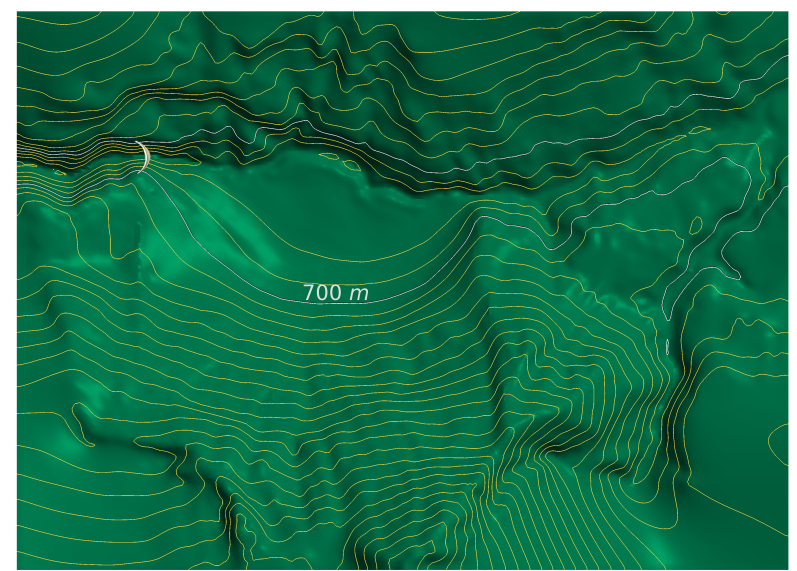

Figure 5: View from the top of the mountain contours with level curves each $50 \mathrm{~m}$. The curve of level at $700 \mathrm{~m}$ a.s.l. (initial water level in the reservoir) is highlighted with white color.

for the landslide material and the basal surface. The landslide friction, cohesion and density are $\phi_{\text {lan }}=34^{\circ}, c_{\text {lan }}=1000 \mathrm{kPa}$, and $\rho_{\text {lan }}=2400 \mathrm{~kg} / \mathrm{m}^{3}$, respectively. The basal plane was modeled with a reduced friction angle of $\phi_{b a s}=11^{\circ}$ and considering no-slip conditions (Franci et al., 2020). A possible alternative to this would be to use Navier slip conditions for the basal surface (see e.g. Cremonesi et al. (2017)). It is important to remark that the chosen material properties are the same as the residual ones used in Pinyol et al. (2017) and fit into the ranges $5^{\circ}-16^{\circ}$, $4^{\circ}-23^{\circ}$, and $2^{\circ}-36^{\circ}$ proposed for the failure surface by Hendron and Patton (1985), Tika and Hutchinson (1999), and Ferri et al. (2011), respectively.

In Section 4.1.2, a different set of material parameters is considered to better reproduce the behavior of the gravel material used in the pre-event experiments and the numerical simulation is run for a longer time duration (250s).

In all cases, water was modeled as a standard Newtonian fluid with viscosity $\mu_{w}=0.001 P a \cdot s$ and density $\rho_{w}=1000 \mathrm{~kg} / \mathrm{m}^{3}$, and the dam, the opposite mountain slope and the basal block were modeled as rigid bodies with fixed zero velocity.

\subsection{Separated lobes failure}

As mentioned, the pre-event experiments always considered the independent failure of one of the two parts of the landslide embraced by the M-shaped tension crack and separated one 
from the other by the Massalezza creek (Fig. 2a). In this section, we simulate numerically the different scenarios produced by the asynchronous failure of the eastern and western lobes of the rockslide.

In the numerical analysis, the volumes of the lobes were defined as shown in the zenithal view of the computational domain provided in Fig. 4. The eastern lobe is slightly bigger than the western one, having an approximate volume of $150 \cdot 10^{6} \mathrm{~m}^{3}$ ( $54 \%$ of the whole landslide body) versus the about $125 \cdot 10^{6}$ $\mathrm{m}^{3}$ of the western lobe. Remarkably, the volume of each one of these parts of the landslide is larger than the water volume enclosed within the limit of the computational domain (around $91 \cdot 10^{6} \mathrm{~m}^{3}$ ). The eastern and the western lobes were discretized with around 1,506,000 and 1,288,000 4-noded linear tetrahedral elements, respectively, while the water volume was discretized with around 1,120,000 linear tetrahedra. A zoom of the initial meshes used for the two analyses is given in Fig. 6.

(a) Initial mesh for west lobe failure analysis

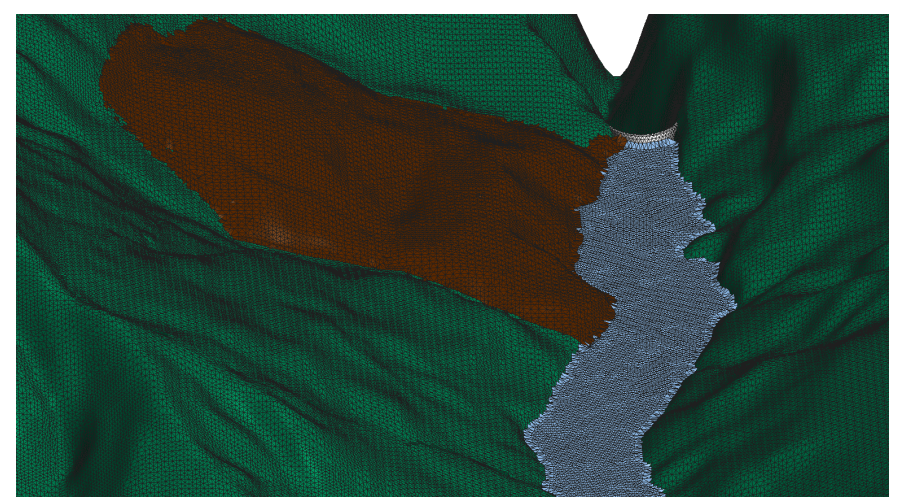

(b) Initial mesh for east lobe failure analysis

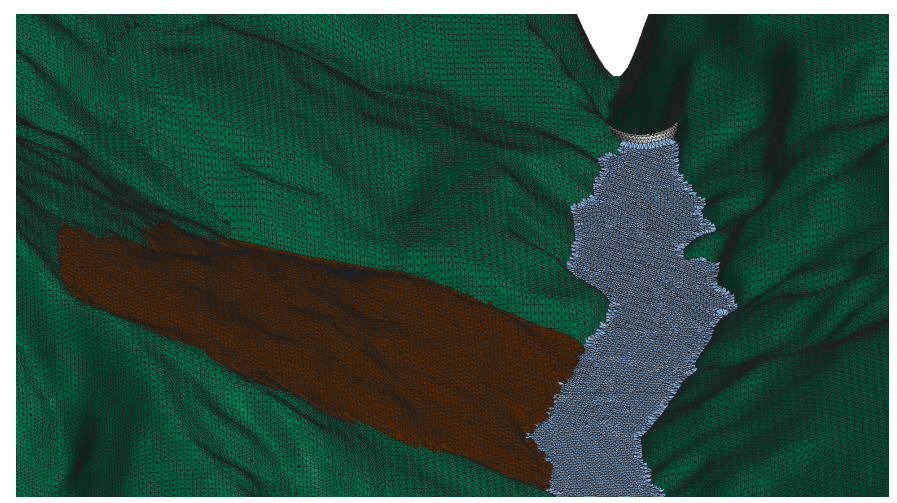

Figure 6: Finite element mesh used for landslide body and water for the separated failure of $(a)$ western $\left(125 \cdot 10^{6} \mathrm{~m}^{3}\right)$ and $(b)$ eastern $\left(150 \cdot 10^{6} \mathrm{~m}^{3}\right)$ lobes.

Two different set of analyses are presented in this section. In Section 4.1.1, the solitary collapse of eastern and western lobes is studied considering the same material parameters used in Franci et al. (2020) for the full rockslide analysis. Then, in Section 4.1.2, the west lobe collapse is analyzed considering a gravel material, mimicking the choice done in the pre-event experiments of Ghetti (1962).

We emphasize that these analyses are not aimed to validate the numerical method against the physical tests of Ghetti (1962) (a thorough validation of the method for landslide impulse wave scenarios has been presented in a companion paper, Franci et al. (2020)), but to investigate the implications of the two main hypotheses assumed in the pre-event experiments, i.e. the collapse of the northern side of M. Toc in two independent landslides and the use of gravel material for the landslide mass.

\subsubsection{Results for rockslide material}

The separated collapse of western and eastern lobes of the Vajont rockslide is here analyzed considering the same set of material parameters used in Franci et al. (2020) for the full rockslide analysis $\left(\phi_{\text {lan }}=34^{\circ}\right.$ and $c_{\text {lan }}=1000 \mathrm{kPa}$ for the landslide body and $\phi_{\text {bas }}=11^{\circ}$ for the failure surface).

Fig. 7 shows the numerical results at four time instants for the solitary failure of western and eastern lobes (on the left and right column, respectively). The velocity contours with a fixed limit of $40 \mathrm{~m} / \mathrm{s}$ are also plotted over the rockslide and water volumes.

The pictures show that the collapse of the eastern lobe induces a more chaotic and critical scenario than the one given by the western lobe failure. The faster sliding of the eastern lobe and the narrowness of the Vajont gorge in that zone (see Fig. 5), increase the impulsive behavior of the two main waves propagating transversally to the landslide motion. One of the waves moves upstream (i.e. eastward) producing a significant water runup over both flanks of the Vajont valley. The other wave propagates westwards and, after around $40 \mathrm{~s}$, it overtops the dam crest with an imponent volume of water (right pictures of Figs. 7c- 7d).

Globally, a water motion with smaller velocities is observed for the collapse of the western lobe. In particular, the water wave propagating upstream (i.e. eastward) reaches velocity peaks of only $25 \mathrm{~m} / \mathrm{s}$, so much less than the $40 \mathrm{~m} / \mathrm{s}$ reached in the eastern lobe case. However, dam overtopping occurs also for the solitary collapse of the western lobe. In this case, the water starts overtopping the dam after only $20 \mathrm{~s}$ and, at $t=40 \mathrm{~s}$, a major volume of water is already flowing through the Vajont gorge towards the Piave Valley (i.e. westward), as shown on the left-hand side of Fig. 7c.

Focusing now on the rockslide dynamics, the velocity distribution obtained for the eastern lobe collapse looks strongly asymmetrical (more than the one obtained for the entire landslide failure, Franci et al. (2020)) and the maximum velocities were recorded along the right-hand (i.e. eastern) side, analogously to the full landslide case (Franci et al., 2020). This is the effect of the geometry of the basal surface that slightly dips to the west, generating a stronger interaction with the left-hand side of the landslide (i.e. the right-hand side of the western lobe which in this simulation remains in place). Instead, the velocity field of the western lobe is much more similar to the one recorded for the full synchronous rockslide scenario (Franci et al., 2020) and this again is a consequence of the failure surface geometry. In fact, as it can be appreciated from Fig. 2a and Fig. 5, the failure surface dips more northward with a small transversal component (smaller than for the eastern lobe failure surface). 
(a) $t=10 \mathrm{~s}$
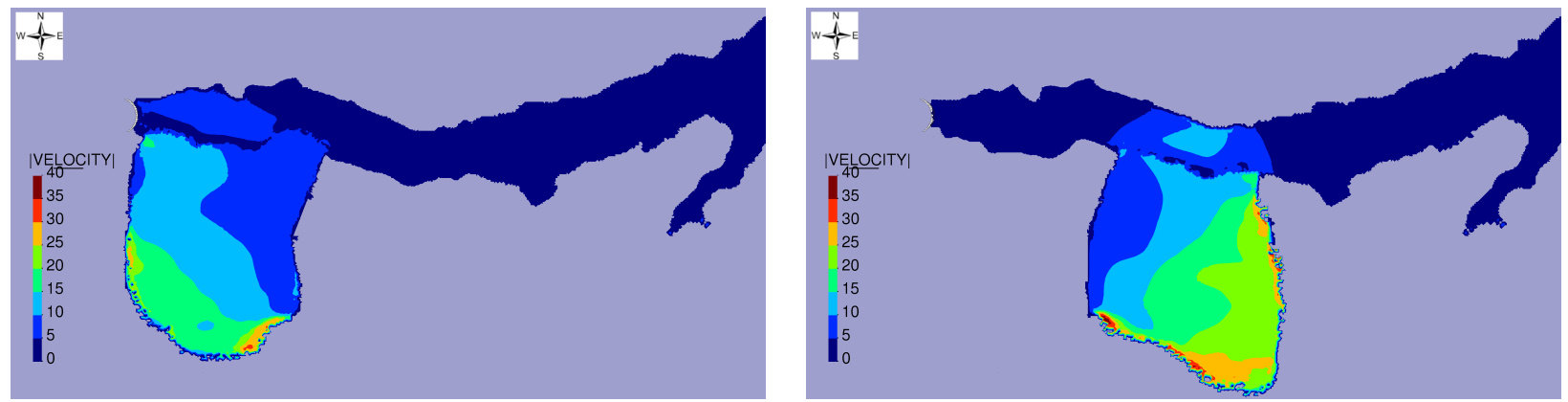

(b) $t=20 \mathrm{~s}$
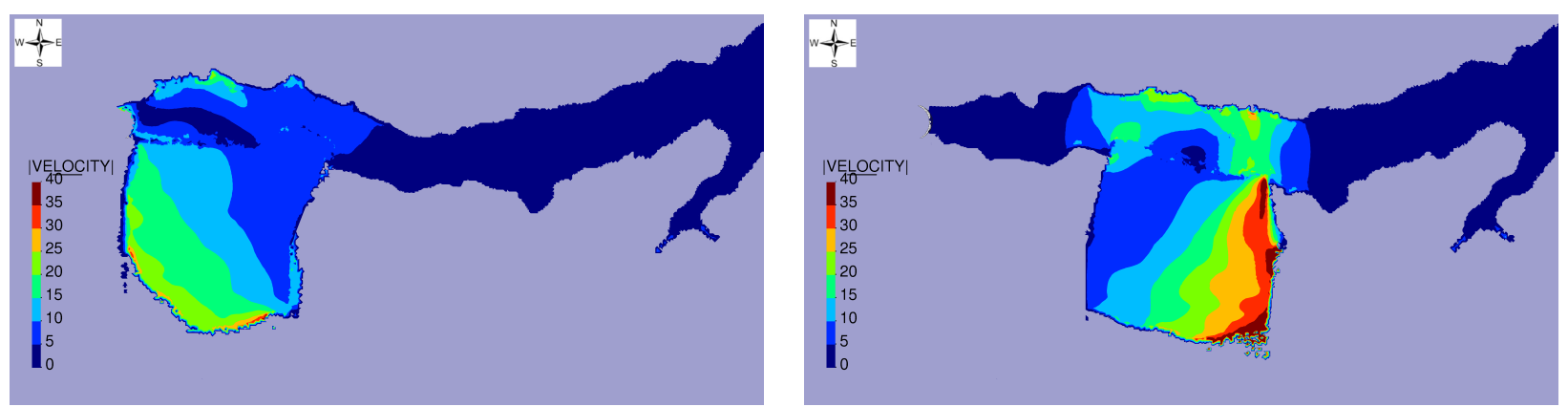

(c) $t=40 \mathrm{~s}$
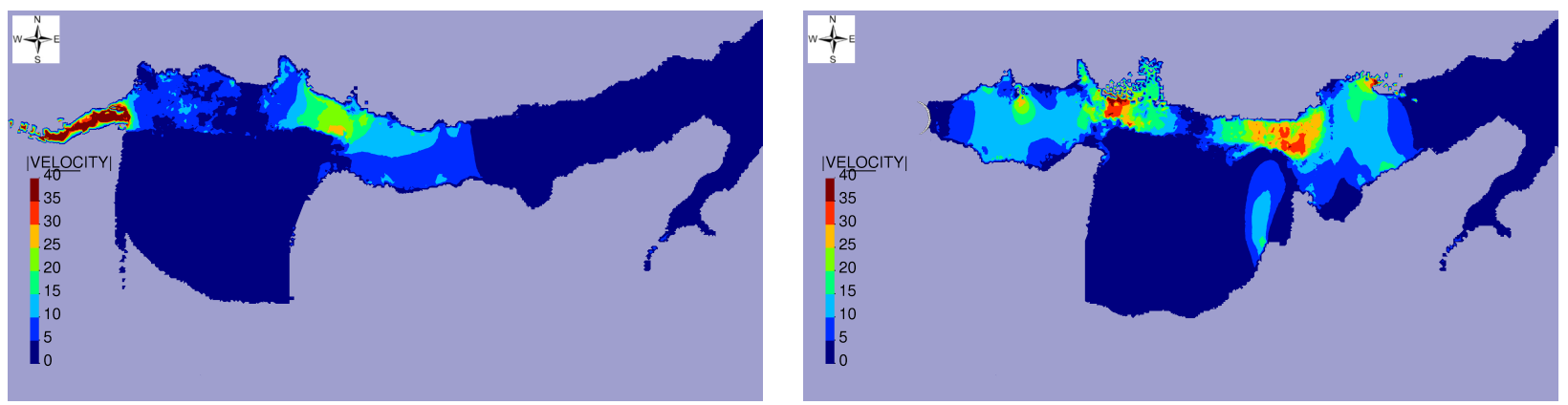

(d) $t=60 \mathrm{~s}$
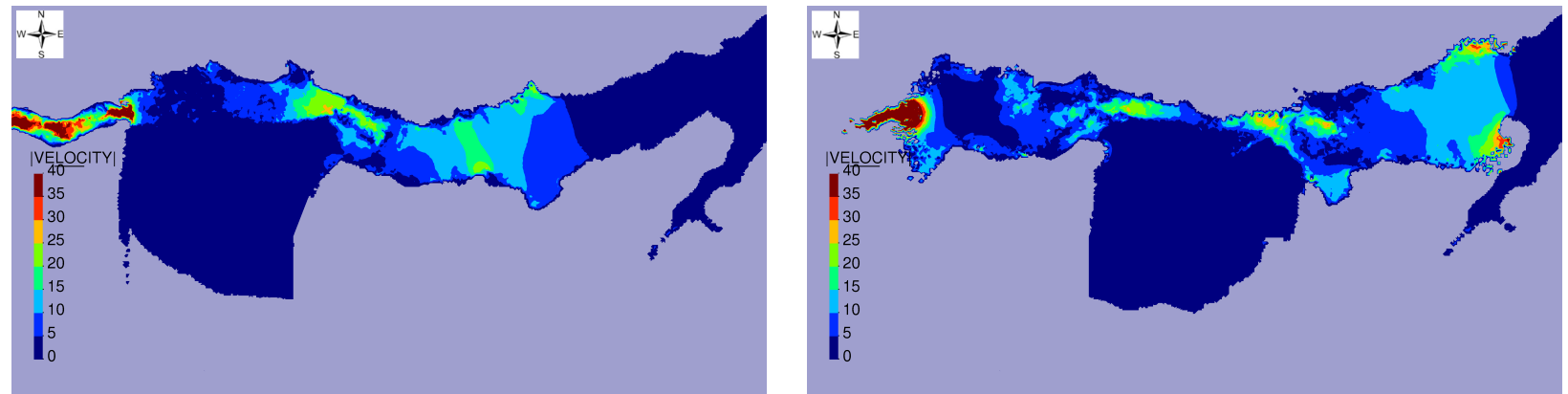

Figure 7: Velocity contours in $\mathrm{m} / \mathrm{s}$ for the sliding of western (left column) and eastern (right column) lobes at four different times. The fixed maximum velocity limit is $40 \mathrm{~m} / \mathrm{s}$. Beyond this value, dark red color is plotted.

In the eastern lobe collapse case, the sliding velocity reaches peaks of $40 \mathrm{~m} / \mathrm{s}$ at the eastern side of the landslide (Fig. 7b) and the complete stoppage of the sliding material occurs after around 40 s, i.e. some 5-10s later than in the whole landslide case (Franci et al., 2020). In the western lobe case, the landslide runout is slower (maximum velocities of around $25 \mathrm{~m} / \mathrm{s}$ ) and stops earlier (after around 30s-35s).

In any case, the sliding duration obtained numerically for the separated collapse of the landslides lobes is much smaller than the one obtained in the pre-event experiments, which was of 
the order of minutes (see Table 1). This aspect will be further discussed in the next subsection.

The graphs of Fig. 8 show the time evolution of the water level (Fig. 8a) and flow rate above the dam (Fig. 8b) obtained for different parts of mobilized material. In the first part of the

(a) Overtopping wave maximum height

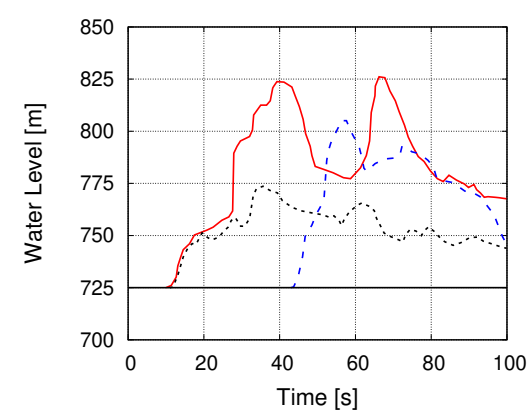
Complete Landslide Only West Lobe Only East Lobe . . . - Dam Crest Level

(b) Flow rate

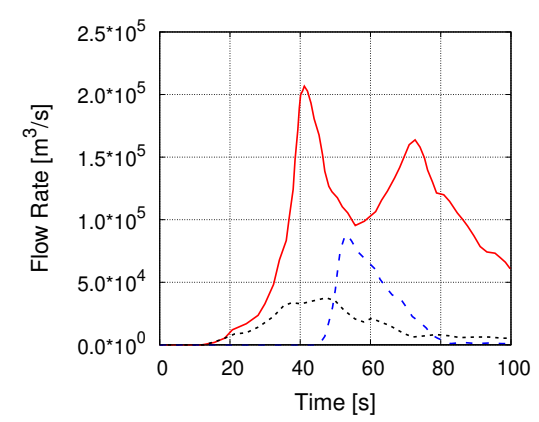

Complete Landslide Only West Lobe ........ Only East Lobe - - - -

Figure 8: Time evolution of the maximum water level and the flow rate above the dam for different portions of mobilized material.

curves, the results of the western lobe and the whole landslide almost overlap. However, at around $t=30 \mathrm{~s}$ the two curves diverge and, while the elevation of the overtopping wave given by the whole landslide keeps increasing, the one given by the western lobe remains at an approximate height of around $30 \mathrm{~m}$ (after reaching a peak value of $45 \mathrm{~m}$ ). On the contrary, the overtopping caused by the eastern lobe collapse starts later (at around $t=40 \mathrm{~s}$ ), but reaches very soon a higher peak value of around $80 \mathrm{~m}$. After that, it decreases quickly reaching a level of $25 \mathrm{~m}$ at $t=100$ s.

These results lead to the counterintuitive conclusion that the collapse of the lobe located farther from the dam (i.e. eastern lobe) would have been the most critical one in terms of water overtopping. Remarkably, the outflow rate given by the eastern lobe collapse has a peak value of around $100 \cdot 10^{3} \mathrm{~m}^{3} / \mathrm{s}$, which is half of that obtained for the whole landslide (Franci et al., 2020), but it doubles the value computed for the western lobe failure. The more severe dam overtopping produced by the eastern lobe can be due to the convex shape of the facing northern flank, resulting in a higher east-west velocity of the tsunami wave, and due to the larger distance to be covered, which allowed the wave to reach its full height. Nevertheless, we note that, also in the less critical case, the obtained overtopping wave height and flow rate over the dam are both more than ten times the values predicted experimentally (Ghetti, 1962).

It is interesting to highlight that the volume of outflow water (computed as the integral of the flow rate) is similar for both the eastern and western lobes failures and their sum is smaller than the case of the full landslide. These results confirm the much more hazardous scenario created by the whole landslide collapse, assuming the same material properties used for the full real event in Franci et al. (2020).

Fig. 9 shows the maximum water runup obtained in the three cases with a continuous line and the observed one with a dashed line.

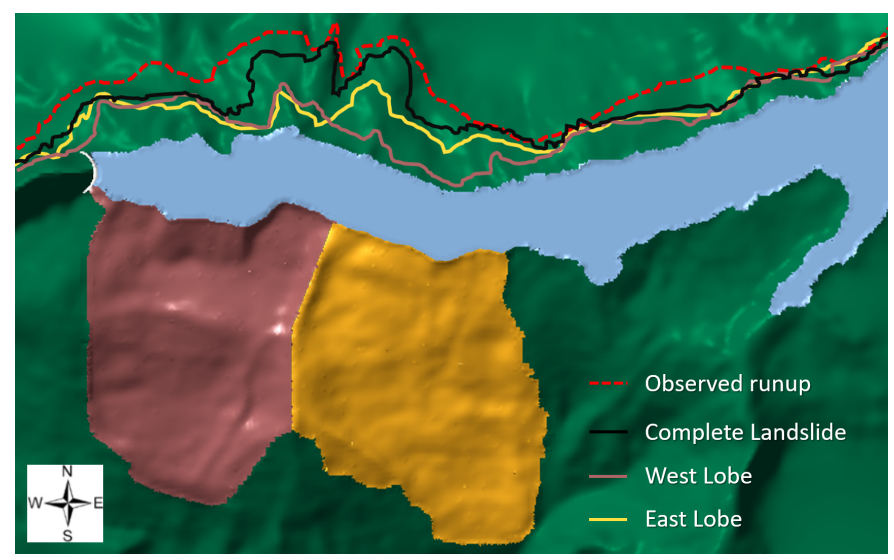

Figure 9: Water runup obtained numerically by separate sliding of east and west lobes compared to the one given by the entire landslide (Franci et al., 2020), and to the observed runup (dashed line).

As already remarked in Franci et al. (2020), the numerical predictions of the complete landslide model slightly underestimate the observed runup, mostly in the area close to the dam, although an overall good agreement is obtained. Comparing the three numerical results, the picture shows sensible differences in the zone in front of the rockslide, where the runup obtained for the full landslide is much higher than the one given by the failure of a single lobe only. Furthermore, the runup given by the collapse of western and eastern lobes is generally similar, although the latter case gives generally a higher runup, especially in the area facing the eastern lobe.

Finally, it is important to quantify the amplitude of the tsunami wave propagating through the lake. For this purpose, Fig. 10 shows the time evolution of the water level at sections $B$, $C$ and $D$ of Fig. 4 for different portions of mobilized material.

The elevation of the dam crest $(725 \mathrm{~m}$ a.s.l.) is also plotted in the graphs. Assuming that any structure and infrastructure should have been built at a higher elevation, the dam crest level is here considered as the safe operational elevation for the whole Vajont reservoir. Based on this assumption, the results of Fig. 10 show that safe conditions could not be achieved for any of the three cases because the water level overcomes the one of the dam at all the three measurement positions. The graphs also confirm that the solitary collapse of the western lobe is the less critical scenario of the three cases. Finally, it should be noted 

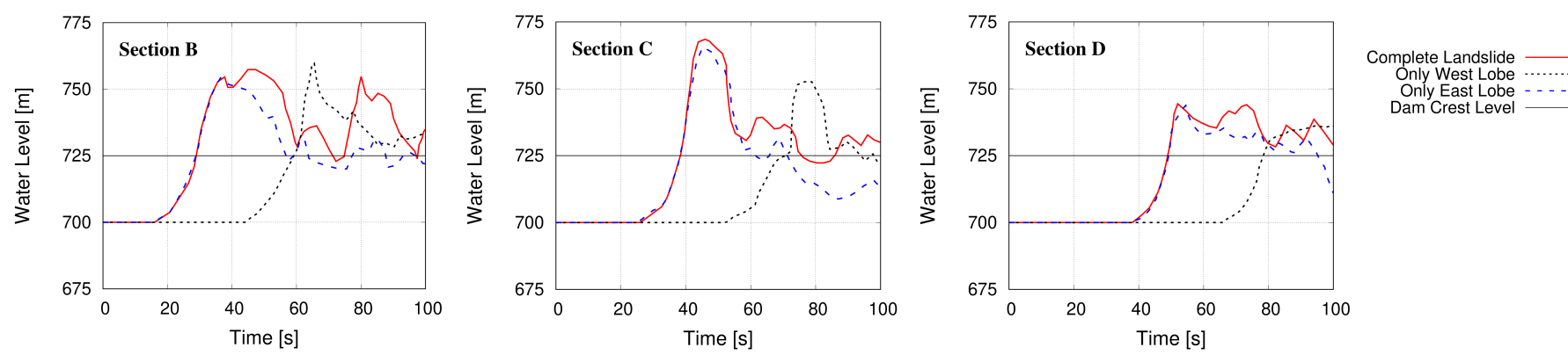

Figure 10: Time evolution of water level at sections $B, C$ and $D$ of Fig. 4 for different portions of mobilized material.

that the first part of the curves of the eastern lobe failure and the complete landslide are practically overlapped. This result demonstrates the crucial role of the eastern part of the landslide on the formation of the main wave propagating upstream.

To sum up, the results presented in this section show that, as expected, the whole landslide event is much more critical than the separate collapse of the landslide lobes, especially in terms of overtopping wave, outflow rate, and runup in the zone in front of the landslide. Instead, fewer differences are exhibited in terms of the tsunami wave propagating eastward. Furthermore, the scenario given by the collapse of the eastern lobe appears to be more critical than the one of the western lobe. This is due not only to its slightly larger initial volume and the higher sliding velocities given by the steeper failure surface but also, as already noted, to the different morphology of the Vajont valley in the zones in front of the eastern and western landslide lobes. As can be appreciated from Fig. 5, in the western part (i.e. closer to the dam), the valley bottom was wider and the northern flank of the valley was characterized by a concave and flatter shape. This configuration facilitates the propagation of the water wave in $S-N$ direction more in the western part than in the eastern one. In fact, the narrowness of the valley in the eastern part facilitates the formation of impulse waves propagating transversally to the landslide motion. Nevertheless, even considering the less critical case, i.e. the collapse of the western lobe, the obtained scenario cannot be considered safe, because dam overtopping is produced also in this case and the tsunami wave propagating in the lake reaches an elevation higher than the dam crest level, which invariably would cause damages.

In all cases, a clear discrepancy versus the pre-event experimental predictions of Ghetti (1962) is found. This result supports the idea that, despite its proven importance, the fact of not considering the whole landslide body cannot explain by itself the differences between the experimental results and the observed data. Other crucial and unfortunate considerations, such as a wrong identification of the sliding material, must be invoked to justify the inaccuracy of the experimental predictions.

\subsubsection{Results for gravel material}

To further investigate the discrepancy between the experimental predictions and both the real event observations and the numerical simulations, the landslide has been modeled considering a material analogous to the loose rounded gravel used in the experimental tests of Ghetti (1962). For the sliding material, a friction angle of $35^{\circ}$ (coherent with the angle of repose of the material), null cohesion and a density of $1800 \mathrm{~kg} / \mathrm{m}^{3}$ were considered. The same friction angle was used also for the failure surface, instead of a reduced value as for the other analyses of this work. Considering the much larger number of experiments analyzing the sole collapse of the western lobe, only the failure of this part of the landslide has been studied. The numerical analysis has been run for a total time duration of $250 \mathrm{~s}$.

In Fig. 11, the numerical results for the western lobe collapse are shown for three time instants.

$$
\text { (a) } t=10 \mathrm{~s}
$$

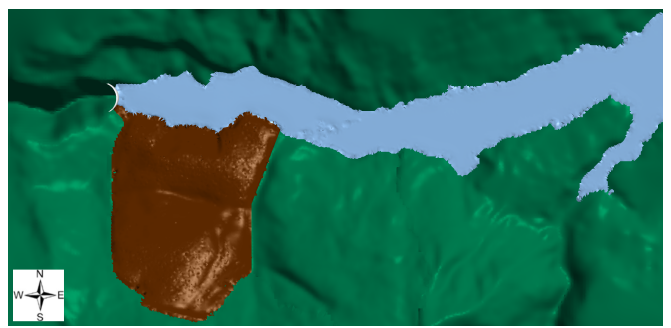

(b) $t=100 \mathrm{~s}$

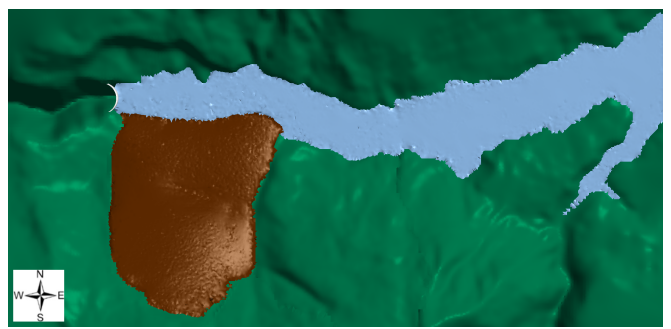

(c) $t=250 \mathrm{~s}$

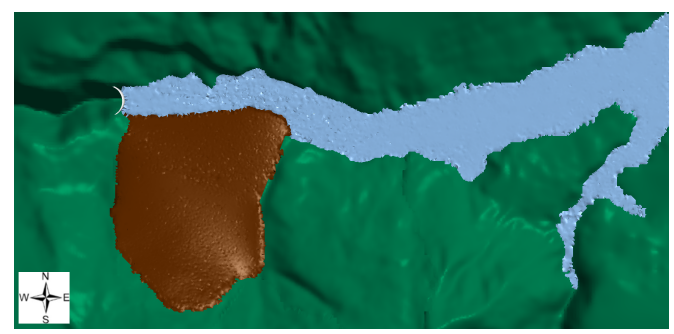

Figure 11: Results of the sliding of western lobe at three time instants considering a gravel material $\left(\phi=35^{\circ}, c=0 P a\right.$, and $\left.\rho=1800 \mathrm{~kg} / \mathrm{m}^{3}\right)$.

The figures depict a much less critical situation than in the 
previous cases showing a reduced motion of the landslide material and a much smaller water runup than the one obtained with more representative material parameters for the rockslide (lefthand side pictures of Fig. 7). Remarkably, dam overtopping is not produced along with the whole duration of the analysis. Due to the reduced thrust of the sliding mass, the impounded volume of water flows away upstream (eastward) after encountering the opposition of the dam at the western side and the opposite bank of the reservoir at the northern side. This result agrees qualitatively with what was obtained in the pre-event experimental tests, where dam overtopping was not observed with the solitary collapse of the western lobe (Table 1).

In Fig. 12, the velocity norm contours are plotted on the cross-section $A$ of Fig. 4 for the same three time instants considered in the plan view of Fig. 11. The initial configuration is also provided to better appreciate the deformation and motion of landslide and water bodies (Fig. 12a).

$$
\text { (a) } t=0 \mathrm{~s}
$$

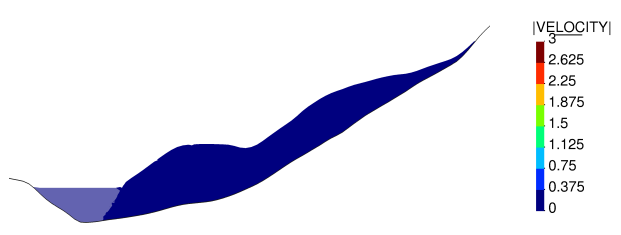

(b) $t=10 \mathrm{~s}$

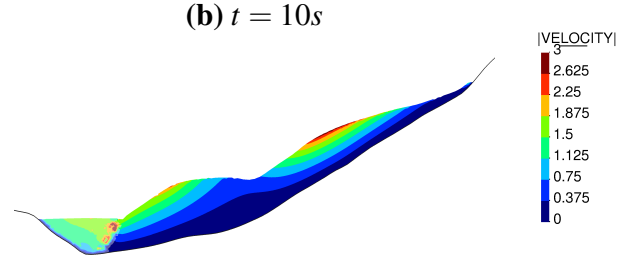

(c) $t=100 \mathrm{~s}$

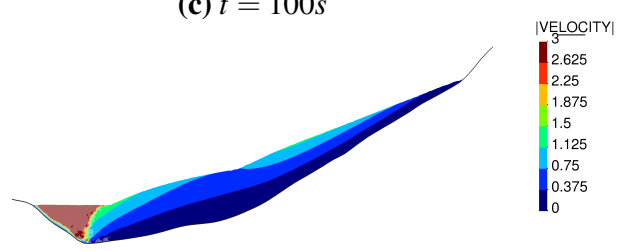

(d) $t=250 \mathrm{~s}$

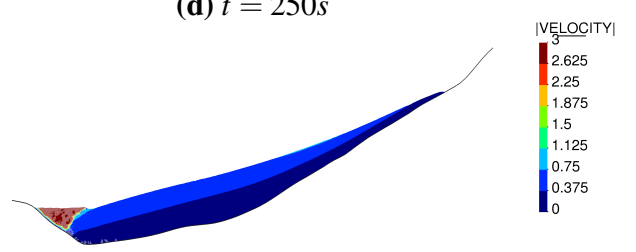

Figure 12: Sliding of western lobe considering a gravel material ( $\phi=35^{\circ}, c=0 P a$, and $\rho=1800 \mathrm{~kg} / \mathrm{m}^{3}$ ). Velocity norm contours (unit $\mathrm{m} / \mathrm{s}$ ) on section $A$ of Fig. 4 at four time instants. Beyond $3 \mathrm{~m} / \mathrm{s}$, dark red color is plotted.

The figures show that the failure mainly occurs, almost separately, in the lower and upper sectors, controlled by the local slope. The upper sector fails and stops at the top of the lower sector. The lower slope (the front of the Vajont rockslide model) fails directly in the lake with a subcircular instability. Hence, the global instability is only partial occurring and at a much lower velocity. Remarkably, the maximum velocities reached by the landslide are smaller than $3 \mathrm{~m} / \mathrm{s}$, much less than the peak values of $20-25 m / s$ obtained in the previous cases. After $250 s$, the sliding maximum velocities are everywhere smaller than $1 \mathrm{~m} / \mathrm{s}$ and the front of the landslide has almost reached the opposite bank of the reservoir. From this we can deduce that the landslide is close to stop its motion. The resulting sliding time duration is thus much longer than the one obtained with the more realistic rockslide material parameters (around 30s-40s), and it is closer to the landslides durations measured in pre-event experimental tests of Ghetti (1962). Fig. 12 also shows that the water level varies slightly during the landslide motion, confirming the higher steadiness of the granular slide scenario.

In Fig. 13, the time evolution of the maximum water level measured at section $B$ of Fig. 4 is plotted. The results obtained using a gravel sliding material are compared to the ones obtained in Section 4.1.1 considering the rockslide material parameters. The graph shows that the upstream wave produced by the gravel landslide keeps always under the dam crest elevation (safe level) reaching a peak amplitude of around $13 m$, which is almost five times smaller than the one obtained with the realistic set of parameters for the rockslide. Also for this measure, the numerical results are close to the experimental observations of Table 1 .

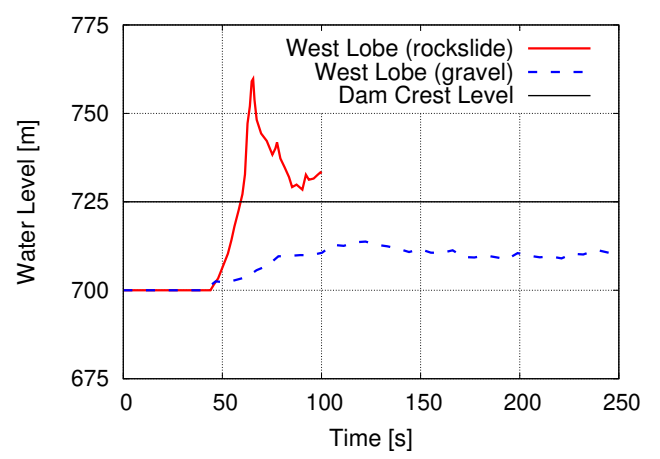

Figure 13: Maximum water level measured at section $B$ of Fig. 4 for western lobe collapse considering rockslide and gravel material parameters.

Table. 2 summarizes the main results obtained for all the analyses presented in this section.

In summary, the numerical results obtained considering a gravel sliding material, initial water level of $700 \mathrm{~m}$, and only the western lobe of the landslide, depict a scenario of absolute safety for the reservoir (at least within the spatial and temporal limits of the computational analysis). In fact, dam overtopping does not occur and the upstream wave has a reduced magnitude. This situation agrees well with the predictions of Ghetti (1962) but is far from the much more critical scenario presented in Section 4.1.1 and obtained considering more realistic material parameters for the rockslide, proving the considerable impact of using in the pre-event physical model a sliding material not representative of the actual one and of its very unique behavior (i.e. causing an extremely rapid evolution).

In this respect, it is worth to remark that the two sets of ma- 


\begin{tabular}{cccccc} 
Landslide volume & \multicolumn{2}{c}{ Landslide dynamics } & \multicolumn{2}{c}{ Maximum wave amplitude } & Overtopping time \\
\hline & Duration & Max. velocities & At the dam & Sections $A, B, C$ & \\
\hline Complete & $35 \mathrm{~s}$ & $40 \mathrm{~m} / \mathrm{s}$ & $125 \mathrm{~m}$ & $70 \mathrm{~m}$ & $15 \mathrm{~s}$ \\
East lobe & $40 \mathrm{~s}$ & $40 \mathrm{~m} / \mathrm{s}$ & $100 \mathrm{~m}$ & $65 \mathrm{~m}$ & $45 \mathrm{~s}$ \\
West lobe & $35 \mathrm{~s}$ & $25 \mathrm{~m} / \mathrm{s}$ & $75 \mathrm{~m}$ & $60 \mathrm{~m}$ & $15 \mathrm{~s}$ \\
West lobe (granular material) & $250 \mathrm{~s}$ & $3 \mathrm{~m} / \mathrm{s}$ & $15 \mathrm{~m}$ & $15 \mathrm{~m}$ & - \\
\hline
\end{tabular}

Table 2: Summary of the numerical results of the analyses of Section 4.1.

terial parameters differ mainly for the used value of the friction angle of the failure surface. In the analyses of Section 4.1.1, following the literature, a reduced friction angle of $11^{\circ}$ was used for the failure surface while, for the granular flow analysis, a unique friction angle of $35^{\circ}$ was used for the whole sliding material. This analysis puts in evidence once again the crucial role of the slip surface material in the Vajont disaster dynamics as already highlighted in several previous studies of Vajont rockslide, e.g. in Hendron and Patton (1985), Nonveiller (1987), Tika and Hutchinson (1999), and Pinyol et al. (2017).

\subsection{Analysis of different initial reservoir levels}

The study presented in this section aims to understand what could have been a reliable safe water level of the Vajont reservoir versus an impulse wave scenario. For this purpose, the collapse of the full landslide body was simulated for three initial water levels $(h)$ in the reservoir, namely $625 \mathrm{~m}, 650 \mathrm{~m}$ and $675 \mathrm{~m}$. The results are here analyzed together with those obtained in Franci et al. (2020) for the actual initial water level $(h=700 \mathrm{~m})$.

We note that these analyses were carried out assuming that the same landslide volume would have been triggered independently on the reservoir water level.

Fig. 14 shows the time evolution of the maximum water elevation and flow rate above the dam for the four different initial reservoir levels. The first significant conclusion that can be drawn from the graphs is that dam overtopping occurs in all cases, although with delay and reduced magnitudes for lower initial water levels.

The graphs of $h=675 m$ and $h=700 m$ show two peaks of similar magnitudes after about $40 \mathrm{~s}$ and $70 \mathrm{~s}$. On the other hand, the curves $h=625 \mathrm{~m}$ and $h=650 \mathrm{~m}$ are smoother and show only a main peak at around $t=70 \mathrm{~s}$. In these cases, the overtopping occurs when the landslide has almost stopped and its body filled the part of the lake placed in front of the dam. Instead, for $h=675 m$ and $h=700 m$, a huge dam overtopping wave has already formed during the landslide motion.

The obtained maximum (rounded) of the overflow rate values are $200 \cdot 10^{3}, 120 \cdot 10^{3}, 60 \cdot 10^{3}$, and $23 \cdot 10^{3} \mathrm{~m}^{3} / \mathrm{s}$ for $h=700,675,650$ and $625 m$, respectively. These values, on the one hand, confirm that the magnitude of dam overtopping is mitigated by reducing the initial reservoir level and, on the other hand, show that, even with a much lower water level than the one present at the moment of the disaster, the water volume overtopping the Vajont dam would have been considerable. This applies particularly for initial water levels $h=675 \mathrm{~m}$ and $h=650 \mathrm{~m}$. Nevertheless, also the scenario given by $h=625 \mathrm{~m}$ (a) Overtopping wave maximum height
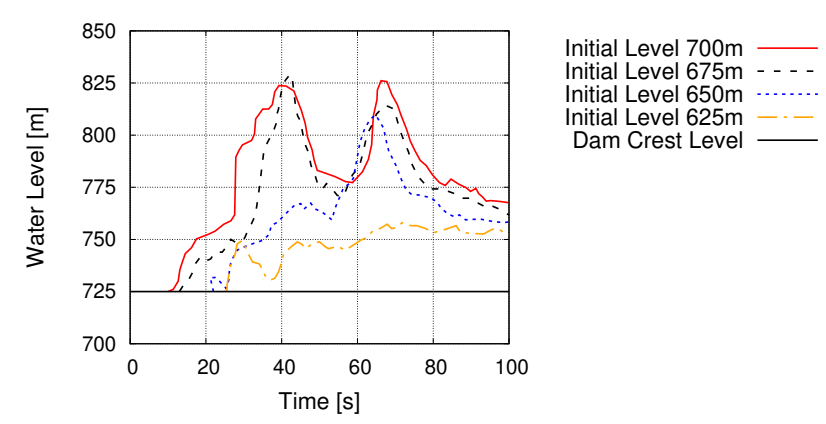

(b) Flow rate

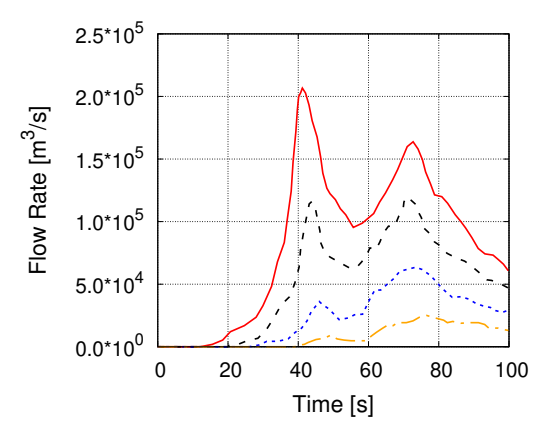

Initial Level 700m Initial Level $675 \mathrm{~m}$ - - - Initial Level $650 \mathrm{~m}$........ Initial Level 625m

Figure 14: Time evolution of water level and flow rate above the dam for different initial reservoir levels.

should be considered critical as the wave level above the dam crest reaches about $25 \mathrm{~m}$ and stays at that level for a long time interval (from around $t=40 \mathrm{~s}$ until the end of the numerical analysis, $t=100 s$ ).

Fig. 15 shows a top view of the numerical results obtained with the four different initial reservoir levels at $t=70 \mathrm{~s}$. This time instant was chosen because it corresponds to (almost) the maximum flow rate out from the dam for all cases (see Fig. 14). The pictures show that the effect of the initial water reservoir on the final rockslide configuration is minimum. Indeed the final deposit of the landslide is very similar in the four cases. On the other hand, the initial reservoir level has an evident effect on the magnitude of the water runup.

To further highlight this aspect, Fig. 16 shows the evolution in time of the maximum wave height (first row) and the water altitude a.s.l. (second row) at sections $B, C$ and $D$ (Fig. 4), for different values of $h$. The graph also shows the dam crest level 
(a) Initial water level: $700 m$ a.s.l.

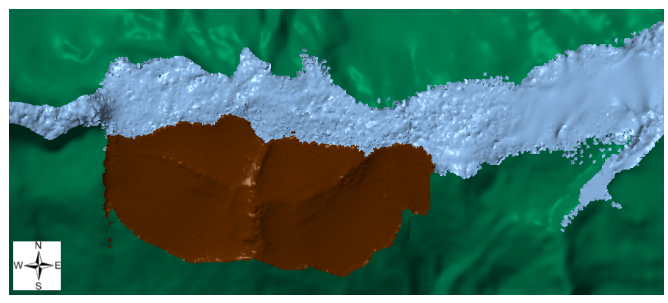

(b) Initial water level: $675 m$ a.s.l.

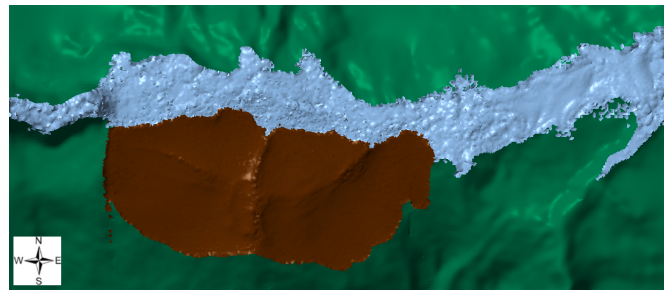

(c) Initial water level: $650 \mathrm{~m}$ a.s.l.

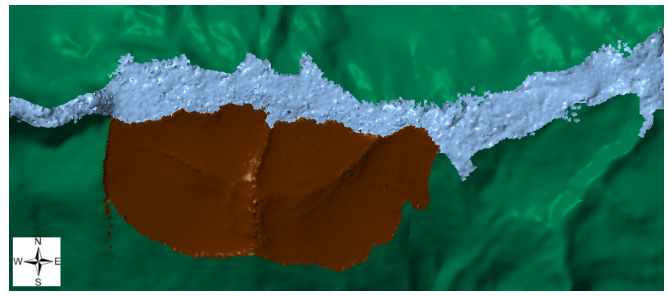

(d) Initial water level: $625 m$ a.s.l.

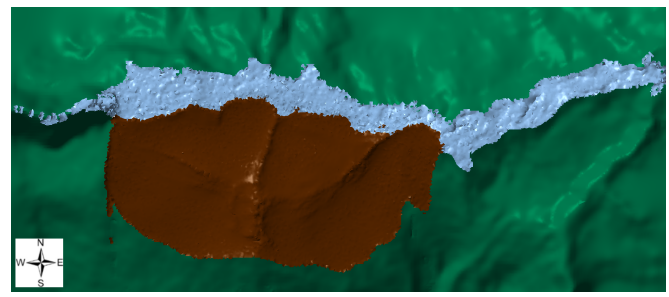

Figure 15: Results at $t=70 \mathrm{~s}$ for four different initial water levels of the hydroelectric reservoir.

considered in the previous analyses as the limit for the safety of the human environment along the shoreline against the propagation of an impulse wave in the reservoir.

As expected, the maximum water elevation increases with the higher initial water level (graphs on the second row of Fig. 16). Nevertheless, it is interesting to note that the amplitude of the maximum wave does not show a clear dependency on the initial water level (first row of Fig. 16).

Comparing the maximum water level given by each case to the safe limit represented by the dam crest level, only the cases with $h=650 m$ and $h=625 m$ can be considered as safe versus the upstream wave propagation. Instead, for $h=675 m$ and $h=700 m$ the safety along the eastern shoreline of the reservoir cannot be guaranteed.

Fig. 17 collects the maximum water levels reached at the dam position and at three locations along with the eastern sector of the reservoir (sections $B, C$ and $D$ of Fig. 4). Remarkably, the water level close to the dam is about $100 \mathrm{~m}$ higher than the maximum elevation reached at the eastern side, for all the cases analyzed. The results at sections $B, C$ and $D$ show that the maximum water level increases almost linearly with the initial water level, whereas the envelope of the measures at the dam position shows a saturation starting from the water level of $675 \mathrm{~m}$.

The main conclusion drawn from the analyses presented in this section is that, under the assumption of a fixed landslide volume with a constant material behavior notwithstanding the changes in the hydraulic boundary conditions (e.g. lake level and degree of saturation, i.e. water content in the landslide material), none of the scenarios obtained for the reduced initial water levels can be considered absolutely safe. In fact, the numerical analyses showed that dam overtopping would be produced in all cases, even for a water level $75 \mathrm{~m}$ lower than the one present in the Vajont reservoir at the moment of the rockslide (700m a.s.l.) (Fig. 14). Different considerations can be done focusing on wave propagating upstream, because, for initial water levels of $650 \mathrm{~m}$ or lower, the obtained water runup was always lower than the dam altitude (725m a.s.l.) and, so, the lake shoreline environment could be considered safe versus the wave propagating upstream. Conversely, for $h \geq 675 m$ this limit is exceeded and the safety conditions could be not guaranteed not even in the eastern part of the Vajont.

\section{Conclusions}

Multi-hazards slope stability problems can generate extremely complex scenarios that are difficult to be analyzed in all their parts. We presented the numerical simulation of different scenarios of the Vajont landslide (1963), putting particular emphasis on reproducing the configurations analyzed on a scaled physical model before the event (Ghetti, 1962), which lead to the wrong conclusion of considering a water altitude of $700 m$ a.s.l. as a safe operational level for the Vajont reservoir. The numerical analyses are performed with the PFEM, an efficient Lagrangian computational method for large deformation problems in solid and fluid mechanics.

The accuracy and robustness of the PFEM for the simulation of impulse waves generated by propagating landslides were assessed in a companion paper with a full 3D analysis of the Vajont disaster (Franci et al., 2020). The results agreed with post-event observations and other numerical analyses. These numerical results were used as reference for the analyses here presented.

In the first part of this work, the separated collapse of the eastern and western lobes of the landslide was analyzed in order to reproduce the scenarios considered in the experimental tests ran before the Vajont disaster. In the beginning, the sliding material was analyzed considering a set of material properties representative of the actual rockslide behavior and identical to the one used in the companion paper. This study showed that, although the scenario created by the collapse of only a half of the landslide is much less critical than the one produced by the full sliding volume, the safety conditions of the reservoir could not have been guaranteed, even in this less hazardous situation (collapse of only the western lobe). In fact, in all cases, a significant 

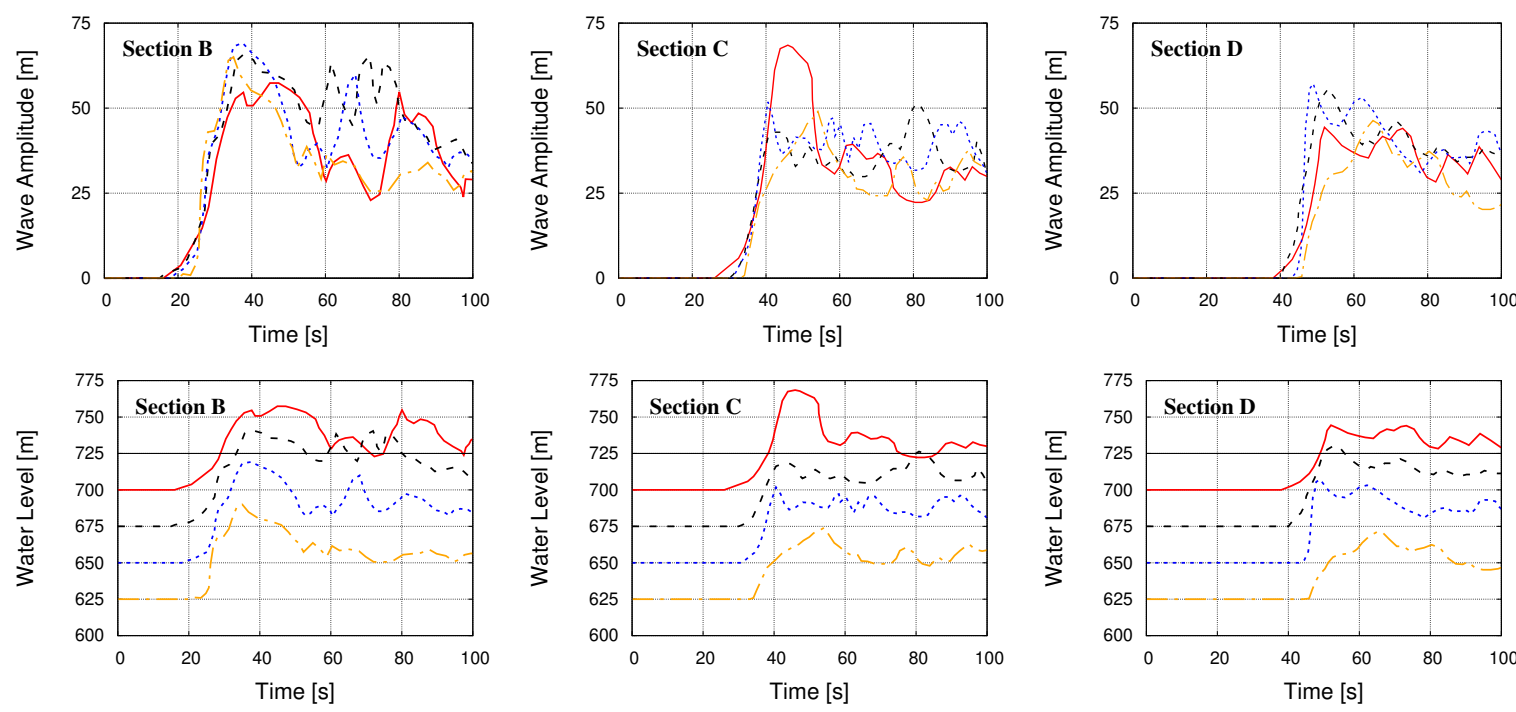
Initial Level $700 \mathrm{~m}-$
Initial Level $675 \mathrm{~m}-\cdots$ Initial Level $650 \mathrm{~m}$ Dam Crest Level

Figure 16: Time evolution of the maximum wave amplitude (first row) and water level (second row) measured at sections $B, C$ and $D$ of Fig. 4 .

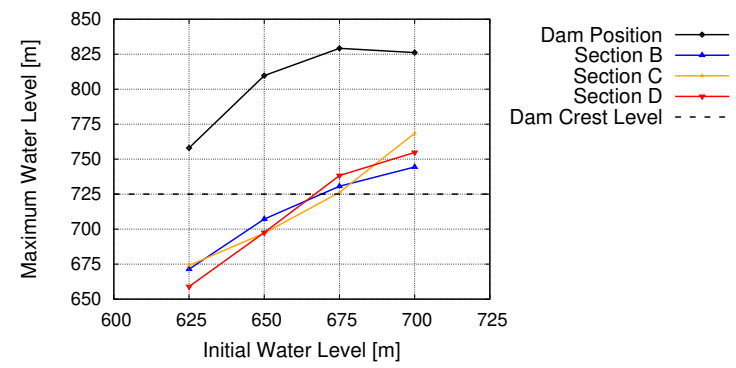

Figure 17: Maximum water level measured at four different positions (at the dam and at sections $B, C$ and $D$ of Fig. 4) for the four different initial water levels analyzed $(h=625 \mathrm{~m}, 650 \mathrm{~m}, 675 \mathrm{~m}$ and $700 \mathrm{~m})$.

water volume overtopped the dam and the induced runup along the lake shoreline could have threatened the built and natural environment. The results differ substantially with the output of the pre-event experiments, supporting the idea that the inadequacy of those experimental predictions cannot be explained by the fact that the complete landslide body was not considered in the experiments.

To further investigate this issue, the collapse of the western lobe was then analyzed using gravel for the sliding material, mimicking the experimental setup. This study showed that, under these conditions, the landslide moved much slower, dam overtopping was not produced, and the water runup on the reservoir shoreline was limited and always below the dam crest level, which may be considered as the safety limit for the reservoir. In this case, the obtained results agreed well with the pre-event experiments.

In conclusion, these analyses showed that the wrong selection of the sliding material affected much more the multi-hazard scenario prediction than the incorrect interpretation of the sliding body volume. These numerical results allow us to speculate that a correct modeling of landslide material and failure surface in the pre-event experiments would have led to not consider
$700 m$ a.s.l. as a safe level for the water reservoir, even considering just a half of the sliding body.

The determination of the best operational safe water level versus an impulse wave scenario was investigated in the second part of this work, where the Vajont disaster was reproduced considering the whole landslide body but varying the initial water level. The analyses showed that the overtopping of the dam would have occurred even for an initial water level $75 \mathrm{~m}$ lower than the actual one at the time of the Vajont rockslide failure (700m a.s.l.), although with a much lower magnitude. On the other hand, analyzing the wave propagating upstream, for initial reservoir levels equal to or lower than 650 m a.s.l., the maximum water elevation resulted always lower than the dam level (within the limits of the computational domain considered in this study), ensuring the safety conditions of the lake shoreline.

From a broader perspective, this work highlights the support that reliable numerical methods can provide to stakeholders' decisions on specific environmental hazards, such as landslide impulse-wave events or other cascade-like phenomena.

Acknowledgements This research was supported by the Spanish Ministry of Economy and Competitiveness (Ministerio de Economia y Competitividad, MINECO) through the Severo Ochoa Programme for Centres of Excellence in R\&D (CEX2018-000797-S) and the project PRECISE (BIA201783805-R), the CARIPLO Project 2016-0769 - DARFLISDistributed quantitative risk Analysis for Rapid Flow-like Landslides induced by high Intensity Storms, the Project MIUR - Dipartimenti di Eccellenza 2018-2022, and the PRIN2017 project XFAST-SIMS: Extra fast and accurate simulation of complex structural systems (D41F19000080001). 


\section{References}

Bosa, S., Petti, M., 2011. Shallow water numerical model of the wave generated by the Vajont landslide. Environmental Modelling \& Software 26, 406-418.

Bosa, S., Petti, M., 2013. A numerical model of the wave that overtopped the Vajont dam in 1963. Water Resources Management 27, 1763-1779.

Brezzi, F., Fortin, M., 1991. Mixed And Hybrid Finite Element Methods. Springer, New York.

Broili, L., 1967. New knowledges on the geomorphology of the vaiont slide slip surfaces. Rock Mech. Eng. Geol. 5, 38-88.

Ciabatti, M., 1964. La dinamica della frana del Vaiont. volume XXXII (I). Giornale di Geologia.

Cremonesi, M., Ferri, F., Perego, U., 2017. A basal slip model for lagrangian finite element simulations of 3D landslides. International Journal for Numerical and Analytical Methods in Geomechanics 41, 30-53.

Cremonesi, M., Franci, A., Idelsohn, S., Oñate, E., 2020. Review of the Particle Finite Element Method. Archives of Computational Methods in Engineering https://doi.org/10.1007/s11831-020-09468-4.

Cremonesi, M., Frangi, A., Perego, U., 2011. A Lagrangian finite element approach for the simulation of water-waves induced by landslides. Computer and Structures 89, 1086-1093.

Crosta, G., Imposimato, S., Roddeman, D., 2016. Landslide spreading, impulse water waves and modelling of the Vajont rockslide. Rock Mechanics and Rock Engineering 49(6), 2413-2436.

Datei, C., 1969. Su alcune questioni di carattere dinamico relative ad un eccezionale scoscendimento di un ammasso roccioso. Memorie della Accademia Patavina, Padova.

Dykes, A., Bromhead, E., 2018. The Vaiont landslide: re-assessment of the evidence leads to rejection of the consensus. Landslides 15, 1815-1832.

Edelsbrunner, H., Mucke, E., 1999. Three dimensional alpha shapes. ACM Transactions on Graphics (TOG) 13 (1), 43-72.

Edelsbrunner, H., Tan, T., 1993. An upper bound for conforming delaunay triangulations. Discrete and Computational Geometry 10 (2), 197:213.

Ferri, F., Toro, G.D., Hirose, T., Han, R., Noda, H., Shimamoto, T., Rossi, N.D., 2011. Low-to-high-velocity frictional properties of the clay-rich gouges from the slipping zone of the 1963 Vaiont slide, northern italy. Journal of Geophysical Research: Solid Earth 116:B09208.

Franci, A., Cremonesi, M., 2019. 3D regularized $\mu$ (i)-rheology for granular flows simulation. Journal of Computational Physics 378, 257-277.

Franci, A., Cremonesi, M., Perego, U., Oñate, E., Crosta, G., 2020. 3D simulation of Vajont disaster. part 1: Numerical formulation and validation. Submitted to Engineering Geology .

Franci, A., Oñate, E., Carbonell, J., 2016. Unified Lagrangian formulation for solid and fluid mechanics and FSI problems. Computer Methods in Applied Mechanics and Engineering 298, 520-547.

Franci, A., Zhang, X., 2018. 3D numerical simulation of free-surface Bingham fluids interacting with structures using the PFEM. Journal of NonNewtonian Fluid Mechanics 259, 1-15.

Ghetti, A., 1962. Esame sul modello degli effetti di un'eventuale frana nel lago-serbatoio del Vajont. Costruzioni Idrauliche dell'Università di Padova. Centro modelli idraulici E. Scimemi S.A.D.E. Rapporto interno inedito 10, 23.

Gingold, R., Monaghan, J., 1977. Smoothed particle hydrodynamics - theory and application to non-spherical stars. Monthly Notices of the Royal Astronomical Society 20, 375-389.

Hendron, A., Patton, F., 1985. The Vaiont slide, a geotechnical analysis based on new geological observations of the failure surface. volume Tech Rep GL85-5, vol 2. Department of the Army, US Corps of Engineers, Washington, $\mathrm{DC}$

ICOLD, . https://www.icold-cigb.org/article/gb/world_register/general_synthesis/number of-dams-by-country-members.

Idelsohn, S., Oñate, E., Pin, F.D., 2004. The particle finite element method: a powerful tool to solve incompressible flows with free-surfaces and breaking waves. International Journal for Numerical Methods in Engineering 61, 964-989.

Manenti, S., Amicarelli, A., Todeschini, S., 2018. WCSPH with limiting viscosity for modeling landslide hazard at the slopes of artificial reservoir. Water $10(4), 515$.

Manenti, S., Pierobon, E., Gallati, M., Sibilla, S., D’Alpaos, L., Macchi, E., Todeschi, S., 2016. Vajont disaster: Smoothed particle hydrodynamics modeling of the postevent 2D experiments. Journal of Hydraulic Engineering 142 (4), 0501500
Massironi, M., Zampieri, D., Superchi, L., Bistacchi, A., Ravagnan, R., Bergamo, A., Ghirotti, M., Genevois, R., 2013. Geological structures of the vajont landslide. Italian journal of engineering geology and environment 6 , 573-582.

Muller, L., 1964. The rock slide in the Vajont valley. Felsmechanik und Ingenieur Geologie.

Mulligan, R., Franci, A., Celigueta, M., Take, W., 2020. Simulations of landslide wave generation and propagation using the Particle Finite Element Method. Journal of Geophysical Research: Oceans 125, e2019JC015873.

Nonveiller, E., 1987. The Vajont reservoir slope failure. Engineering Geology. Dam Failures 24, 493 - 512.

Osher, S., Fedkiw, R., 2006. Level Set Methods and Dynamic Implicit Surfaces. Springer edition.

Oñate, E., Franci, A., Carbonell, J., 2014. Lagrangian formulation for finite element analysis of quasi-incompressible fluids with reduced mass losses. International Journal for Numerical Methods in Fluids 74 (10), 699-731.

Oñate, E., Idelsohn, S., Pin, F.D., Aubry, R., 2004. The particle finite element method. An overview. International Journal for Computational Methods 1, 267-307.

Paronuzzi, P., Rigo, E., Bolla, A., 2013. Influence of filling-drawdown cycles of the Vajont reservoir on mt. toc slope stability. Geomorphology 191, 7593.

Pinyol, N., Alvarado, M., Alonso, E., Zabala, F., 2017. Thermal effects in landslide mobility. Géotechnique, 1-18.

Pudasaini, S., Mergili, M., 2019. A multi-phase mass flow model. Journal of Geophysical Research: Earth Surface 124(12), 2920-2942.

Rossi, D., Semenza, E., 1965. Carte geologiche del versante settentrionale del M. Toc e zone limitrofe, prima e dopo il fenomeno di scivolamento del 9 Ottobre 1963. Scala 1:5000. volume Ist. Geol. Univ. Ferrara, Italy.

Rossi, D., Semenza, E., 1986. Carta geologica del versante settentrionale del M. Toc e zone limitrofe. volume Le foto della frana del Vajont. Masè G, Semenza M, Semenza P, Semenza P, Turrini MC, 2004, Le foto della frana del Vajont.

Salazar, F., Irazabal, J., Larese, A., Oñate, E., 2016. Numerical modelling of landslide-generated waves with the particle finite element method (PFEM) and a non-Newtonian flow model. International Journal for Numerical and Analytical Methods in Geomechanics 40, 809-826.

Selli, R., Trevisan, G., 1964. La frana del Vaiont. volume Serie 2(32). Giornale di Geologia, Annali del Museo Geologico di Bologna.

Semenza, E., 1965. Sintesi degli studi geologici sulla frana del Vaiont dal 1959 al 1964. volume 16. Mem Mus Trident Sci Nat, A XXIX-XXX.

Tika, T., Hutchinson, J., 1999. Ring shear tests on soil from the Vaiont landslide slip surface. Géotechnique 49(1), 59-74.

Vacondio, R., Mignosa, P., Pagani, S., 2013. 3D SPH numerical simulation of the wave generated by the Vajont rockslide. Advances in water resources $59,146-156$.

Viparelli, M., Merla, G., 1968. L'onda di piena seguita alla frana del Vajont. Università degli Studi di Napoli.

Voight, B., Faust, C., 1982. Frictional heat and strength loss in some rapid landslides. Géotechnique 32, 43-54.

Ward, S., Day, S., 2008. Tsunami balls: A granular approach to tsunami runup and inundation. Communications in Computational Physics 10, 222-249.

Ward, S., Day, S., 2011. The 1963 landslide and flood at Vaiont reservoir italy. a tsunami ball simulation. Italian Journal of Geoscience 130 (1), 16-26.

Zhang, X., Oñate, E., Galindo, S., Bleyer, J., Krabbenhoft, K., 2019. A unified lagrangian formulation for solid and fluid dynamics and its possibility for modelling submarine landslides and their consequences. Computer Methods in Applied Mechanics and Engineering 343, 314-338. 